\title{
PERIODIC SOLUTIONS OF PERIODIC GENERALIZED FOOD LIMITED MODEL
}

\author{
YONGKUN LI
}

(Received 14 December 1999)

\begin{abstract}
By using the continuation theorem of coincidence degree theory, the existence of positive periodic solutions for a periodic generalized food limited model with state dependent delays and distributed delays is studied, respectively.
\end{abstract}

2000 Mathematics Subject Classification. Primary 34K13.

1. Introduction. Gopalsamy, Kulenović, and Ladas [4] studied the existence of periodic solutions of the following periodic food limited model:

$$
\frac{d N(t)}{d t}=r(t) N(t)\left[\frac{K(t)-N(t-m \omega)}{K(t)+c(t) r(t) N(t-m \omega)}\right],
$$

where $K, r, c$ are continuous positive $\omega$-periodic functions, $m$ is a positive integer. Also, since as it was indicated by Freedman and $\mathrm{Wu}$ [1] that it would be of interesting to study the existence of periodic solutions for population models with periodic delays; and since at present, there are only a few papers which have been published on the existence of periodic solutions of state dependent delay differential equations (see [6] and references therein). Our main purpose in this paper is-by using the Mawhin's continuation theorem of coincidence degree theory $[2,10]$-to establish the existence of positive periodic solutions for the periodic generalized food limited model

$$
\frac{d N(t)}{d t}=r(t) N(t)\left[\frac{K(t)-N(t)-\sum_{j=1}^{n} a_{j}(t) N\left(t-\tau_{j}(t, N(t))\right)}{1+r(t) \sum_{j=1}^{n} b_{j}(t) N\left(t-\sigma_{j}(t, N(t))\right)}\right]^{\theta}
$$

with state dependent delays and

$$
\frac{d N(t)}{d t}=r(t) N(t)\left[\frac{K(t)-N(t)-\sum_{j=1}^{n} a_{j}(t) \int_{-l_{j}}^{0} N(t+s) d \eta_{j}(s)}{1+r(t) \sum_{j=1}^{n} b_{j}(t) \int_{-h_{j}}^{0} N(t+s) d \mu_{j}(s)}\right]^{\theta}
$$

with distributed delays, where $K>0, r>0, a_{j} \geq 0, b_{j} \geq 0(j=1,2, \ldots, n)$ are continuous $\omega$-periodic functions, $\tau_{j}, \sigma_{j} \in C\left(R^{2}, R\right)(j=1,2, \ldots, n)$ are $\omega$-periodic with respect to their first arguments, respectively, $l_{j}, h_{j}(j=1,2, \ldots, n)$ are positive constants, $\eta_{j}, \mu_{j}(j=1,2, \ldots, n)$ are nondecreasing with respect to their arguments, respectively, and $\theta$ is a positive odd number. As a special case of (1.2), we also obtain 
the existence of periodic solutions of the following generalized food limited model with periodic delays

$$
\frac{d N(t)}{d t}=r(t) N(t)\left[\frac{K(t)-N(t)-\sum_{j=1}^{n} a_{j}(t) N\left(t-\tau_{j}(t)\right)}{1+r(t) \sum_{j=1}^{n} b_{j}(t) N\left(t-\sigma_{j}(t)\right)}\right]^{\theta},
$$

where $K>0, r>0, a_{j} \geq 0, b_{j} \geq 0, \tau_{j}, \sigma_{j}(j=1,2, \ldots, n)$ are continuous $\omega$-periodic functions, and $\theta$ is a positive odd number. For the ecological sense of (1.4), we refer to [3] and the references therein. For some work concerning the existence of periodic solutions of functional differential equations which was done by using the Mawhin's coincidence degree theory we refer to $[5,7,8,9]$.

2. Main results. In this section, by using the Mawhin continuation theorem we show the existence of at least one positive periodic solution of (1.2) and (1.3). To do so, we first make some preparations.

Let $X, Y$ be real Banach spaces, $L:$ Dom $L \subset X \rightarrow Y$ a Fredholm mapping of index zero, and $P: X \rightarrow X, Q: Y \rightarrow Y$ continuous projectors such that $\operatorname{Im} P=\operatorname{Ker} L, \operatorname{Ker} Q=$ $\operatorname{Im} L$, and $X=\operatorname{Ker} L \oplus \operatorname{Ker} P, Y=\operatorname{Im} L \oplus \operatorname{Im} Q$. Denote by $L_{P}$ the restriction of $L$ to $\operatorname{Dom} L \bigcap \operatorname{Ker} P, K_{P}: \operatorname{Im} L \rightarrow \operatorname{Ker} P \bigcap \operatorname{Dom} L$ the inverse (to $L_{P}$ ), and $J: \operatorname{Im} Q \rightarrow \operatorname{Ker} L$ an isomorphism of $\operatorname{Im} Q$ onto $\operatorname{Ker} L$.

For convenience, we introduce the continuation theorem [2, page 40] as follows.

LEMMA 2.1. Let $\Omega \subset X$ be an open bounded set and $N: X \rightarrow Y$ be a continuous operator which is L-compact on $\bar{\Omega}$ (i.e., $Q N: \bar{\Omega} \rightarrow Y$ and $K_{P}(I-Q) N: \bar{\Omega} \rightarrow Y$ are compact). Assume

(i) for each $\lambda \in(0,1), x \in \partial \Omega \bigcap \operatorname{Dom} L, L x \neq \lambda N x$;

(ii) for each $x \in \partial \Omega \bigcap \operatorname{Ker} L, Q N x \neq 0$, and $\operatorname{deg}\{J Q N, \Omega \bigcap \operatorname{Ker} L, 0\} \neq 0$.

Then $L x=N x$ has at least one solution in $\bar{\Omega} \bigcap \operatorname{Dom} L$.

In what follows, we use the notation

$$
\bar{u}=\frac{1}{\omega} \int_{0}^{\omega} u(t) d t, \quad|u|_{0}=\max _{t \in[0, \omega]}|u(t)|,
$$

where $u$ is a continuous $\omega$-periodic function.

We are now in a position to state and prove our first main result.

THEOREM 2.2. Equation (1.2) has at least one positive w-periodic solution.

Proof. Consider the following equation

$$
\frac{d x(t)}{d t}=r(t)\left[\frac{K(t)-e^{x(t)}-\sum_{j=1}^{n} a_{j}(t) \exp \left(x\left(t-\tau_{j}\left(t, e^{x(t)}\right)\right)\right)}{1+r(t) \sum_{j=1}^{n} b_{j}(t) \exp \left(x\left(t-\sigma_{j}\left(t, e^{x(t)}\right)\right)\right)}\right]^{\theta},
$$

where $K, r, a_{j}, b_{j}, \tau_{j}, \sigma_{j}(j=1,=2, \ldots, n)$ and $\theta$ are the same as those in (1.2). It is easy to see that if (2.2) has an $\omega$-periodic solution $x^{*}(t)$, then $N^{*}(t)=\exp \left(x^{*}(t)\right)$ is a positive $\omega$-periodic solution of (1.2). So, to complete the proof, it suffices to show that (2.2) has an $\omega$-periodic solution. 
In order to use the continuation theorem of coincidence degree theory to establish the existence of $\omega$-periodic solution of (2.2), we take $X=Y=\{x(t) \in C(R, R)$ : $x(t+\omega)=x(t)\}$. With the norm $|\cdot|_{0}, X$ is a Banach space. Set

$$
L: \operatorname{Dom} L \bigcap X, \quad L x=\frac{d x}{d t}
$$

where $\operatorname{Dom} L=\left\{x(t) \in C^{1}(R, R)\right\}$, and

$$
N: X \rightarrow X, \quad N x=r(t)\left[\frac{K(t)-e^{x(t)}-\sum_{j=1}^{n} a_{j}(t) \exp \left(x\left(t-\tau_{j}\left(t, e^{x(t)}\right)\right)\right)}{1+r(t) \sum_{j=1}^{n} b_{j}(t) \exp \left(x\left(t-\sigma_{j}\left(t, e^{x(t)}\right)\right)\right)}\right]^{\theta} .
$$

Define two projectors $P$ and $Q$ as

$$
P x=Q x=\frac{1}{\omega} \int_{0}^{\omega} x(t) d t, \quad x \in X .
$$

Clearly, $\operatorname{Ker} L=R, \operatorname{Im} L=\left\{x \in X: \int_{0}^{\omega} x(t) d t=0\right\}$ is closed in $X$ and $\operatorname{dim} \operatorname{Ker} L=$ $\operatorname{codim} \operatorname{Im} L=1$. Hence, $L$ is a Fredholm mapping of index zero. Furthermore, through an easy computation, we find that the inverse $K_{P}$ of $L_{P}$ has the form

$$
\begin{gathered}
K_{P}: \operatorname{Im} L \rightarrow \operatorname{Dom} L \bigcap \operatorname{Ker} P, \\
K_{P}(y)=\int_{0}^{t} x(s) d s-\frac{1}{\omega} \int_{0}^{\omega} \int_{0}^{u} x(s) d s d u, \quad t \in[0, \omega] .
\end{gathered}
$$

Notice that

$$
\begin{gathered}
Q N: X \rightarrow X \\
Q N x=\frac{1}{\omega} \int_{0}^{\omega}\left\{r(t)\left[\frac{K(t)-e^{x(t)}-\sum_{j=1}^{n} a_{j}(t) \exp \left(x\left(t-\tau_{j}\left(t, e^{x(t)}\right)\right)\right)}{1+r(t) \sum_{j=1}^{n} b_{j}(t) \exp \left(x\left(t-\sigma_{j}\left(t, e^{x(t)}\right)\right)\right)}\right]\right\} d t .
\end{gathered}
$$

We find

$$
\begin{gathered}
K_{P}(I-Q) N: X \rightarrow X, \\
x \longmapsto \int_{0}^{t}\left\{r(s)\left[\frac{K(s)-e^{x(s)}-\sum_{j=1}^{n} a_{j}(s) \exp \left(x\left(s-\tau_{j}\left(s, e^{x(s)}\right)\right)\right)}{1+r(s) \sum_{j=1}^{n} b_{j}(s) \exp \left(x\left(s-\sigma_{j}\left(s, e^{x(s)}\right)\right)\right)}\right]^{\theta}\right\} d s \\
-\frac{1}{\omega} \int_{0}^{\omega} \int_{0}^{u}\left\{r(s)\left[\frac{K(s)-e^{x(s)}-\sum_{j=1}^{n} a_{j}(s) \exp \left(x\left(s-\tau_{j}\left(s, e^{x(s)}\right)\right)\right)}{1+r(s) \sum_{j=1}^{n} b_{j}(s) \exp \left(x\left(s-\sigma_{j}\left(s, e^{x(s)}\right)\right)\right.}\right]^{\theta}\right\} d s d u \\
-\left(\frac{t}{\omega}-\frac{1}{2}\right) \int_{0}^{\omega}\left\{r(s)\left[\frac{K(s)-e^{x(s)}-\sum_{j=1}^{n} a_{j}(s) \exp \left(x\left(s-\tau_{j}\left(s, e^{x(s)}\right)\right)\right)}{1+r(s) \sum_{j=1}^{n} b_{j}(s) \exp \left(x\left(s-\sigma_{j}\left(s, e^{x(s)}\right)\right)\right)}\right]^{\theta}\right\} d s .
\end{gathered}
$$

Obviously, $Q N$ and $K_{P}(I-Q) N$ are continuous by the Lebesgue theorem and $Q N(\bar{\Omega}), K_{P}(I-Q) N(\bar{\Omega})$ are relatively compact for any open bounded set $\Omega \subset X$. 
Therefore, $N$ is $L$-compact on $\bar{\Omega}$ for any open bounded set $\Omega \subset X$. Corresponding to the operator equation $L x=\lambda N x, \lambda \in(0,1)$, we have

$$
\frac{d x(t)}{d t}=\lambda\left\{r(t)\left[\frac{K(t)-e^{x(t)}-\sum_{j=1}^{n} a_{j}(t) \exp \left(x\left(t-\tau_{j}\left(t, e^{x(t)}\right)\right)\right)}{1+r(t) \sum_{j=1}^{n} b_{j}(t) \exp \left(x\left(t-\sigma_{j}\left(t, e^{x(t)}\right)\right)\right.}\right]^{\theta}\right\}, \quad \lambda \in(0,1) .
$$

Suppose that $x(t) \in X$ is a solution of (2.9) for some $\lambda \in(0,1)$. Choose $t_{1} \in[0, \omega]$ such that

$$
x\left(t_{1}\right)=\max _{t \in[0, \omega]} x(t)
$$

Then it is clear that

$$
x^{\prime}\left(t_{1}\right)=0 .
$$

In view of this and (2.9), we obtain

$$
r\left(t_{1}\right)\left\{\left[\frac{K\left(t_{1}\right)-e^{x\left(t_{1}\right)}-\sum_{j=1}^{n} a_{j}\left(t_{1}\right) \exp \left(x\left(t_{1}-\tau_{j}\left(t_{1}, e^{x\left(t_{1}\right)}\right)\right)\right)}{1+r\left(t_{1}\right) \sum_{j=1}^{n} b_{j}\left(t_{1}\right) \exp \left(x\left(t_{1}-\sigma_{j}\left(t_{1}, e^{x\left(t_{1}\right)}\right)\right)\right.}\right]^{\theta}\right\}=0
$$

which implies that

$$
K\left(t_{1}\right)-e^{x\left(t_{1}\right)}-\sum_{j=1}^{n} a_{j}\left(t_{1}\right) \exp \left(x\left(t_{1}-\tau_{j}\left(t_{1}, e^{x\left(t_{1}\right)}\right)\right)\right)=0 .
$$

Thus

$$
e^{x\left(t_{1}\right)}<K\left(t_{1}\right) \leq|K|_{0}, \quad x\left(t_{1}\right)<\ln |K|_{0} .
$$

Integrating (2.9) over $[0, \omega]$, we obtain

$$
\int_{0}^{\omega}\left\{r(t)\left[\frac{K(t)-e^{x(t)}-\sum_{j=1}^{n} a_{j}(t) \exp \left(x\left(t-\tau_{j}\left(t, e^{x(t)}\right)\right)\right)}{1+r(t) \sum_{j=1}^{n} b_{j}(t) \exp \left(x\left(t-\sigma_{j}\left(t, e^{x(t)}\right)\right)\right)}\right]^{\theta}\right\} d t=0
$$

which implies that there exist a positive constant $A_{1}$ and a point $t_{0} \in[0, \omega]$ such that

$$
x\left(t_{0}\right)>-A_{1} .
$$

It follows from (2.9) and (2.14) that

$$
\begin{aligned}
\int_{0}^{\omega}\left|\frac{d x(t)}{d t}\right| d t & =\int_{0}^{\omega}\left|r(t)\left[\frac{K(t)-e^{x(t)}-\sum_{j=1}^{n} a_{j}(t) \exp \left(x\left(t-\tau_{j}\left(t, e^{x(t)}\right)\right)\right)}{1+r(t) \sum_{j=1}^{n} b_{j}(t) \exp \left(x\left(t-\sigma_{j}\left(t, e^{x(t)}\right)\right)\right.}\right]^{\theta}\right| d t \\
& <\int_{0}^{\omega}\left|r(t)\left[K(t)-e^{x(t)}-\sum_{j=1}^{n} a_{j}(t) \exp \left(x\left(t-\tau_{j}\left(t, e^{x(t)}\right)\right)\right)\right]^{\theta}\right| d t \\
& <\omega \bar{r}\left(|K|_{0}\right)^{\theta}\left[2+\sum_{j=1}^{n}\left|a_{j}\right|_{0}\right]^{\theta} \stackrel{\text { def }}{=} A_{2} .
\end{aligned}
$$

By this and (2.16), we obtain

$$
x(t)=x\left(t_{0}\right)+\int_{t_{0}}^{t} x^{\prime}(t) d t \geq x\left(t_{0}\right)-\int_{0}^{\omega}\left|x^{\prime}(t)\right| d t>-\left(A_{1}+A_{2}\right) .
$$


Denote by $A=\max \left\{\left.|\ln | K\right|_{0} \mid, A_{1}+A_{2}\right\}+A_{3}$, here $A_{3}>0$ is taken sufficiently large such that $K(t)-e^{A}-e^{A} \sum_{j=1}^{n} a_{j}(t)<0$ and $K(t)-e^{-A}-e^{-A} \sum_{j=1}^{n} a_{j}(t)>0$ for $t \in$ $[0, \omega]$ and take $\Omega=\left\{x(t) \in X:|x|_{0}<A\right\}$, then it is clear that $\Omega$ satisfies condition (i) in Lemma 2.1. When $x \in \partial \Omega \cap R, x$ is a constant with $|x|=A$. Hence,

$$
Q N x=\frac{1}{\omega} \int_{0}^{\omega}\left\{r(t)\left[\frac{K(t)-e^{x}-e^{x} \sum_{j=1}^{n} a_{j}(t)}{1+r(t) e^{x} \sum_{j=1}^{n} b_{j}(t)}\right]^{\theta}\right\} d t \neq 0 .
$$

Furthermore, take $J=I: \operatorname{Im} Q \rightarrow \operatorname{Ker} L, x \mapsto x$, by a straightforward computation, we find

$$
\operatorname{deg}[J Q N, \operatorname{Ker} L \cap \Omega, 0] \neq 0 .
$$

According to Lemma 2.1, we have completed the proof.

Next, immediately, from Theorem 2.2, we have the following corollary.

COROLlary 2.3. Equation (1.4) has at least one positive w-periodic solution.

REMARK 2.4. In (1.4), when $b_{j}(t)=0$ for all $t \in[0, \omega]$ and $j=1,2, \ldots, n$, equation (1.4) becomes the well-known logistic equation with several delays.

Finally, similar to the proof of Theorem 2.2, one can prove the following theorem.

THEOREM 2.5. Equation (1.3) has at least one positive w-periodic solution.

Proof. The proof is similar to the one of Theorem 2.2, to complete the proof, it suffices to show that the following equation:

$$
\frac{d x(t)}{d t}=r(t)\left[\frac{K(t)-e^{x(t)}-\sum_{j=1}^{n} a_{j}(t) \int_{-l_{j}}^{0} e^{x(t+s)} d \eta_{j}(s)}{1+r(t) \sum_{j=1}^{n} b_{j}(t) \int_{-h_{j}}^{0} e^{x(t+s)} d \mu_{j}(s)}\right]^{\theta},
$$

has an $\omega$-periodic solution, where $r, K, \theta, a_{j}, b_{j}, l_{j}, h_{j}, \eta_{j}, \mu_{j}, j=1,2, \ldots, n$ are the same as those in (1.3). To this end, set

$$
N x=r(t)\left[\frac{K(t)-e^{x(t)}-\sum_{j=1}^{n} a_{j}(t) \int_{-l_{j}}^{0} e^{x(t+s)} d \eta_{j}(s)}{1+r(t) \sum_{j=1}^{n} b_{j}(t) \int_{-h_{j}}^{0} e^{x(t+s)} d \mu_{j}(s)}\right]^{\theta}
$$

and $L, P, Q, X$ are the same as those in the proof of Theorem 2.2. Corresponding to the operator equation $L x=\lambda x, \lambda \in(0,1)$, we have

$$
\frac{d x(t)}{d t}=\lambda\left\{r(t)\left[\frac{K(t)-e^{x(t)}-\sum_{j=1}^{n} a_{j}(t) \int_{-l_{j}}^{0} e^{x(t+s)} d \eta_{j}(s)}{1+r(t) \sum_{j=1}^{n} b_{j}(t) \int_{-h_{j}}^{0} e^{x(t+s)} d \mu_{j}(s)}\right]^{\theta}\right\}, \lambda \in[0, \omega] .
$$

Suppose that $x(t) \in X$ is a solution of (2.23) for a certain $\lambda \in(0,1)$. Choose $t^{1} \in[0, \omega]$ such that

$$
x\left(t^{1}\right)=\max _{t \in[0, \omega]} x(t)
$$


Then

$$
x^{\prime}\left(t^{1}\right)=0
$$

By this and (2.23), we have

$$
r\left(t^{1}\right)\left[\frac{K\left(t^{1}\right)-e^{x\left(t^{1}\right)}-\sum_{j=1}^{n} a_{j}\left(t^{1}\right) \int_{-l_{j}}^{0} e^{x\left(t^{1}+s\right)} d \eta_{j}(s)}{1+r\left(t^{1}\right) \sum_{j=1}^{n} b_{j}\left(t^{1}\right) \int_{-h_{j}}^{0} e^{x\left(t^{1}+s\right)} d \mu_{j}(s)}\right]^{\theta}=0,
$$

which implies that

$$
K\left(t^{1}\right)-e^{x\left(t^{1}\right)}-\sum_{j=1}^{n} a_{j}\left(t^{1}\right) \int_{-l_{j}}^{0} e^{x\left(t^{1}+s\right)} d \eta_{j}(s)=0 .
$$

Therefore,

$$
e^{x\left(t^{1}\right)}<K\left(t^{1}\right) \leq|K|_{0}, \quad x\left(t^{1}\right)<\ln |K|_{0} .
$$

Integrating (2.23) over $[0, \omega]$, we have

$$
\int_{0}^{\omega}\left\{r(t)\left[\frac{K(t)-e^{x(t)}-\sum_{j=1}^{n} a_{j}(t) \int_{-l_{j}}^{0} e^{x(t+s)} d \eta_{j}(s)}{1+r(t) \sum_{j=1}^{n} b_{j}(t) \int_{-h_{j}}^{0} e^{x(t+s)} d \mu_{j}(s)}\right]^{\theta}\right\} d t=0,
$$

which implies that there exist a positive constant $B_{1}$ and a point $t^{0} \in[0, \omega]$ such that

$$
x\left(t^{0}\right)>-B_{1} .
$$

In view of (2.23) and (2.28), we obtain

$$
\begin{aligned}
\int_{0}^{\omega}\left|\frac{d x(t)}{d t}\right| d t & =\int_{0}^{\omega}\left|r(t)\left[\frac{K(t)-e^{x(t)}-\sum_{j=1}^{n} a_{j}(t) \int_{-l_{j}}^{0} e^{x(t+s)} d \eta_{j}(s)}{1+r(t) \sum_{j=1}^{n} b_{j}(t) \int_{-h_{j}}^{0} e^{x(t+s)} d \mu_{j}(s)}\right]^{\theta}\right| d t \\
& <\int_{0}^{\omega}\left|r(t)\left[K(t)-e^{x(t)}-\sum_{j=1}^{n} a_{j}(t) \int_{-l_{j}}^{0} e^{x(t+s)} d \eta_{j}(s)\right]^{\theta}\right| d t \\
& <\omega \bar{r}|K|_{0}^{\theta}\left[2+\sum_{j=1}^{n}\left|a_{j}\right|_{0}\right]^{\theta} \stackrel{\text { def }}{=} B_{2} .
\end{aligned}
$$

According to this and (2.30), we have

$$
x(t)=x\left(t^{0}\right)+\int_{t^{0}}^{t} x^{\prime}(t) d t \geq x\left(t^{0}\right)-\int_{0}^{\omega}\left|x^{\prime}(t)\right| d t>-B_{1}-B_{2} .
$$

From this and (2.28) it follows that

$$
|x(t)|_{0}<\max \left\{\left.|\ln | K\right|_{0} \mid, B_{1}+B_{2}\right\} .
$$

The rest of the proof is similar to the one of Theorem 2.2 and will be omitted.

REMARK 2.6. In (1.3), when $b_{j}=0$ for all $j=1,2, \ldots, n$, equation (1.3) becomes the well-known logistic equation with several delays. 
ACKNOWLEDGEMENT. This work was partially supported by the ABF of Yunnan Province of China.

\section{REFERENCES}

[1] H. I. Freedman and J. H. Wu, Periodic solutions of single-species models with periodic delay, SIAM J. Math. Anal. 23 (1992), no. 3, 689-701. MR 93e:92012. Zbl 764.92016.

[2] R. E. Gaines and J. L. Mawhin, Coincidence Degree, and Nonlinear Differential Equations, Lecture Notes in Mathematics, vol. 568, Springer-Verlag, Berlin, New York, 1977. MR 58\#30551. Zbl 339.47031.

[3] K. Gopalsamy, Stability and Oscillations in Delay Differential Equations of Population Dynamics, Mathematics and its Applications, vol. 74, Kluwer Academic Publishers Group, Dordrecht, 1992. MR 93c:34150. Zbl 752.34039.

[4] K. Gopalsamy, M. R. S. Kulenović, and G. Ladas, Environmental periodicity and time delays in a "food-limited" population model, J. Math. Anal. Appl. 147 (1990), no. 2, 545555. MR 91f:92020. Zbl 701.92021.

[5] J. K. Hale and J. Mawhin, Coincidence degree and periodic solutions of neutral equations, J. Differential Equations 15 (1974), 295-307. MR 49\#780. Zbl 274.34070.

[6] J. K. Hale and S. M. Verduyn Lunel, Introduction to Functional-differential Equations, Applied Mathematical Sciences, vol. 99, Springer-Verlag, New York, 1993. MR 94m:34169. Zbl 787.34002.

[7] L. Y. Kun, Periodic solution of a periodic neutral delay equation, J. Math. Anal. Appl. 214 (1997), no. 1, 11-21. MR 99j:34101. Zbl 894.34075.

[8] Y. Li, Periodic solutions of a periodic delay predator-prey system, Proc. Amer. Math. Soc. 127 (1999), no. 5, 1331-1335. MR 99i:34101. Zbl 917.34057.

[9] J. Mawhin, Periodic solutions of some vector retarded functional differential equations, J. Math. Anal. Appl. 45 (1974), 588-603. MR 48\#11725. Zbl 275.34070.

[10] _ Topological Degree Methods in Nonlinear Boundary Value Problems, CBMS Regional Conference Series in Mathematics, no. 40, American Mathematical Society, Providence, R.I., 1979, Expository lectures from the CBMS Regional Conference held at Harvey Mudd College, Claremont, Calif., June 9-15, 1977. MR 80c:47055. Zbl 414.34025.

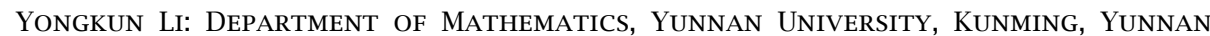
650091, CHINA

E-mail address: yk1ie@ynu.edu.cn 


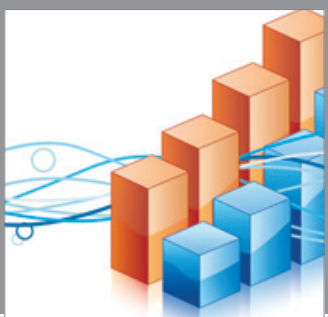

Advances in

Operations Research

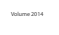

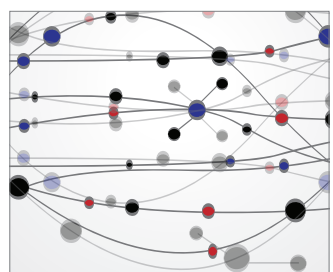

\section{The Scientific} World Journal
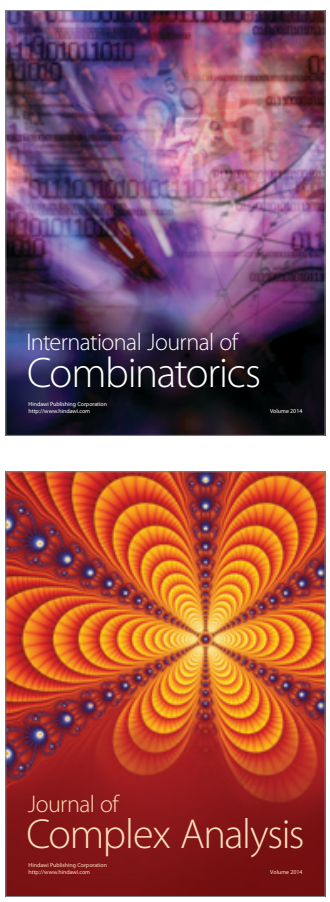

International Journal of

Mathematics and

Mathematical

Sciences
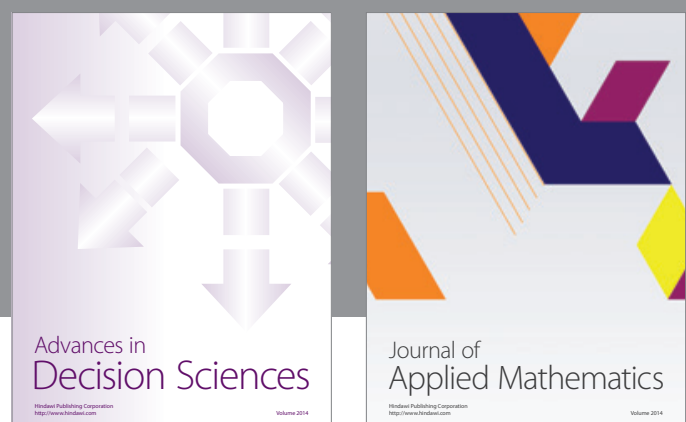

Journal of

Applied Mathematics
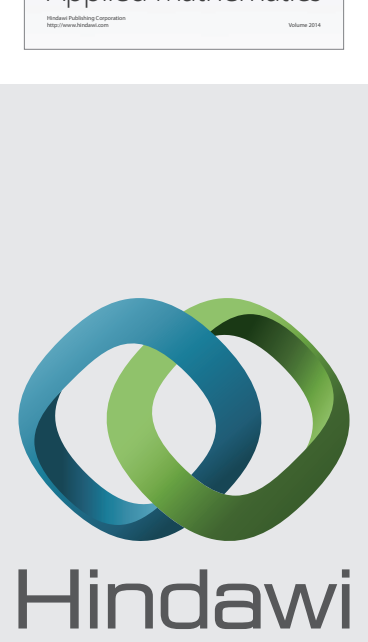

Submit your manuscripts at http://www.hindawi.com
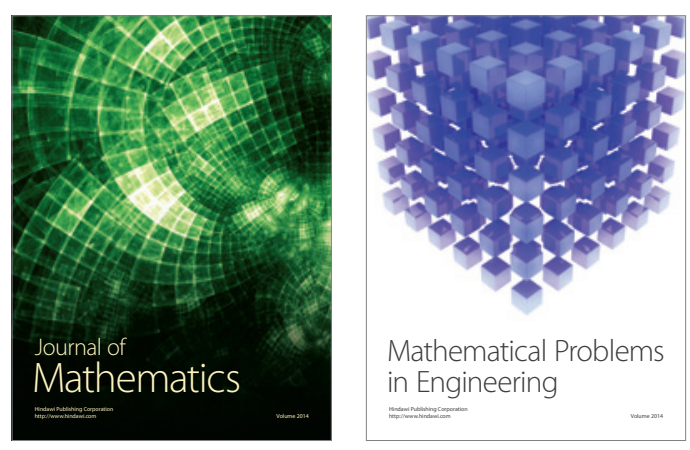

Mathematical Problems in Engineering
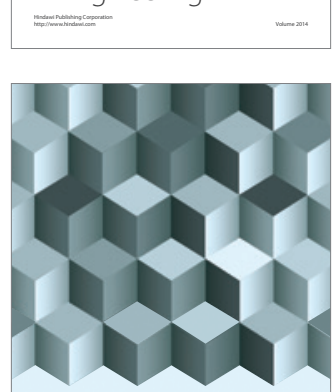

Journal of

Function Spaces
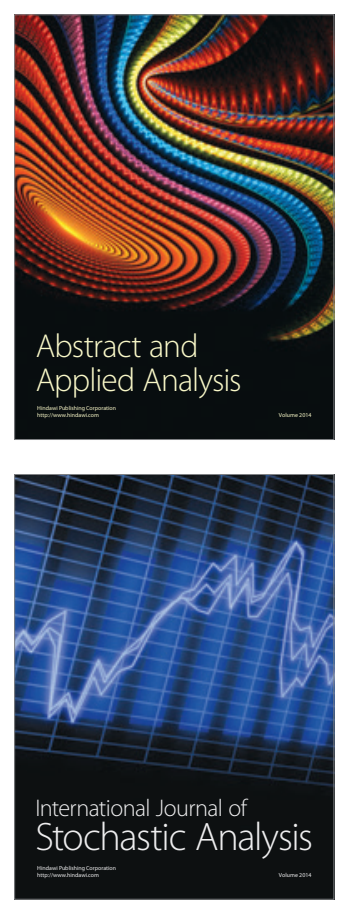

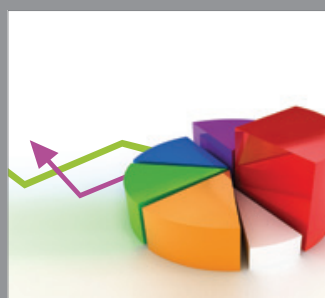

ournal of

Probability and Statistics

Promensencen
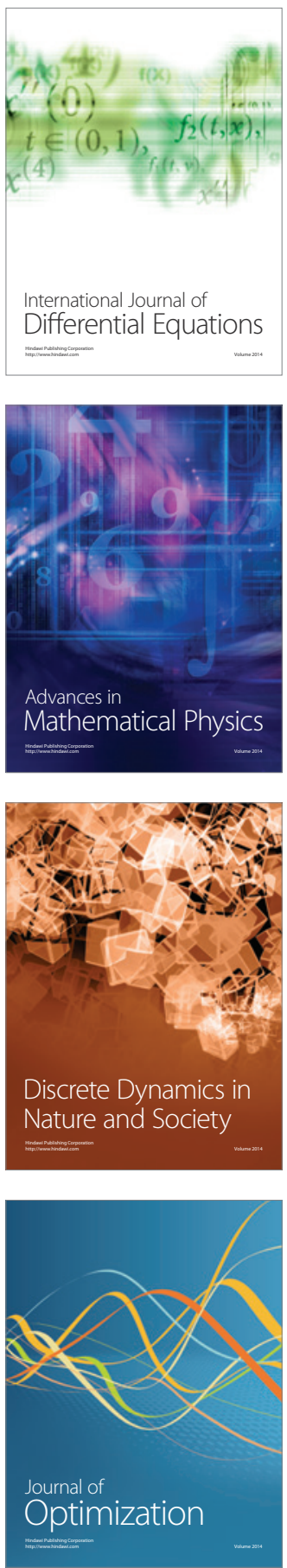